\title{
A QUESTÃO DA DIFERENÇA NA LITERATURA MOÇAMBICANA
}

José Luís Cabaço

Universidade de São Paulo

$\mathrm{E}$

m 1981, seis anos após a independência de Moçambique, o governo tomou a decisão de criar uma televisão nacional. A entidade governamental responsável pelo projeto tinha aproveitado, na fase de preparação da resolução final, um mês de emissões promocionais para realizar uma pesquisa sobre os gostos e expectativas da população em relação ao novo mídia. Fez-se um curto vídeo, numa área da periferia urbana, registrando as reações do público a um western americano e entrevistando, no final, alguns dos espectadores, quase todos jovens, que tinham aderido à projeção com mais evidente entusiasmo. Para grande surpresa de todos nós, nenhum dos entrevistados havia entendido que o filme tinha uma história. Esta constatação foi o início de uma profunda reflexão do grupo de trabalho no decurso da qual tomamos consciência de que, no processo de apropriação do que aqueles espectadores acabavam de ver no ecran, a percepção sensorial antecedia e se sobrepunha à racional. O seu entusiasmo, a alegria demonstrada, a participação intensa do que passava diante dos seus olhos respondia à força intrínseca de cada cena, violenta ou cômica, espetacular ou movimentada. Descreviam as cenas que os haviam impressionado mas eram incapazes de recordar a conexão existente com o que as antecedia ou lhes sucedia.

Estávamos perante uma situação extrema de um dos conflitos emblemáticos da África em transição. Constatávamos a clivagem existente entre dois mundos. De um lado, uma realidade pré-industrial, fundada na oralidade, limitadamente aculturada, em que os fenômenos só ganham sentido quan- 
do, no plano místico ou no plano do concreto, se encaixam na unidade harmônica do seu mundo de certezas. Do outro, uma sociedade culturalmente industrial, impregnada do simbolismo da escrita e da imagem, onde a compreensão dos fenômenos procede da sua abordagem analítica e da dúvida como pressuposto de método.

Os espectadores/camponeses, porque a linguagem cinematográfica seguia princípios e regras semânticas cuja gênese e cujas referências se situavam na sociedade industrial e, portanto, no exterior do próprio patrimônio cultural, não dispunham de elementos para decifrar o conteúdo. As cenas surgiam-lhes, assim, isoladas, apenas inteligíveis nalguns dos seus elementos e, principalmente, quando as variáveis de espaço e de tempo eram fixas. Em síntese, a linguagem cinematográfica era tão pouco compreensível para a massa dos neoespectadores quanto a linguagem escrita para a multidão dos analfabetos.

O debate alargou-se, por conseqüência, para a necessidade de se repensarem os ritmos, a utilização do tempo e espaço, as acentuações narrativas, o valor dos símbolos, em função de um espectador com o qual era essencial aprender muito para saber como ajudá-lo a descodificar a imagem.

Esta descoberta da profundidade da diferença passava-se num país marcado, na véspera da independência, por uma taxa de analfabetismo que atingia $92 \%$ dos seus, então, 12 milhões de habitantes. Cerca de 10\% da população vivia em zonas urbanas, a quase totalidade nas áreas periféricas de cidades e vilas ocupadas pelos colonos. Não havia televisão e a rádio era o único mídia tecnológico que cobria os centros urbanos e sensivelmente metade das zonas rurais. Ao cabo de 500 anos de soberania portuguesa, que na realidade foram pouco mais de 100 anos, as populações negras que habitavam o território de Moçambique continuavam vivendo, não por incompetência do colonialismo mas por uma deliberada política de dominação, numa sociedade dominantemente oral.

"Miséria do povo, opressão nacional e inibição da cultura, são uma e a mesma coisa”, sintetizou Franz Fanon (s.d., p.233).

A experiência de intervenção na área cultural evidenciava cada dia que a noção de diferença, palavra estigmatizada pelo discurso hegemônico, estava indissociavelmente contida no conceito de periferia. A África era e é naturalmente marcada pela diferença em relação à referência universal do mundo em que somos periferia: o da cultura euro-americana. 
A dominação colonial foi o instrumento essencial desse processo de periferização. A história recente de Moçambique, antes da independência, evidencia como as formas de expressão cultural pré-industriais foram irremediavelmente segregadas.

Aquilo que o sistema português considerava "cultura", sempre sob a austera vigilância da censura oficial, cingia-se à produção artística, literária e científica, de matriz ocidental, levada a cabo na sociedade urbana. O espaço criativo, limitado pelos gostos de um público em que a cultura do ocupante era hegemônica, desempenhava, entre outras, a função de aproveitar os talentos e aptidões para afirmar a supremacia da cultura do colono junto das minorias africanas alfabetizadas e, deste modo, reforçar a política de assimilação.

Opunham-se duas sociedades, como já referi, dois estágios de desenvolvimento, dois modos de estar na vida, constituindo, num mesmo território, as duas margens divididas pela águas caudalosas do desconhecimento $\mathrm{e}$ da exclusão.

Foi logicamente no movimento cultural das cidades que os primeiros intelectuais moçambicanos, mestiços e negros, se foram paulatinamente afirmando. Deste período, no primeiro quarto de século de 1900, destacam-se os textos vigorosos dos irmãos João e José Albasini e de Estácio Dias nas páginas do seu jornal $O$ Brado Africano. A palavra escrita revelou-se a forma mais direta de exprimir as sofridas angústias, de denunciar as iniqüidades e injustiças, de fazer ouvir a própria voz. Os textos desses intelectuais assimilados, veiculados através da imprensa, dirigiam-se ao colonizador reclamando um espaço na sociedade urbana e moderna ao qual, como burguesia nascente e como elite iluminada, se sentiam com direito. Esmeravam-se no uso da língua portuguesa porque não se podiam permitir que uma imprecisão formal os desqualificasse como assimilados ou comprometesse o valor da sua argumentação.

O sistema respondia com a repressão e, acentuando a diferença, discriminava-os racialmente e remetia-os para a periferia social. A sua discriminação, portanto, não se fundamentava na diversidade de comportamentos, mas sim na cor da pele.

Naquele contexto, gradualmente adquire consciência de que, a despeito de sua cultura urbana, ele nunca seria aceite como cidadão pleno, mas seria sempre visto como diferente, como colonizado. No mundo implantado 
na terra dos seus ancestrais, descobre-se forasteiro. Guetizado na margem moderna da sociedade, o intelectual amadureceu a reflexão sobre a sua condição, refinou o estilo, clandestinizou o gesto. Em busca de novos caminhos, o jornalista torna-se escritor.

A gente a que ele pertence está, afinal, do outro lado desse rio do desconhecimento, na margem dos excluídos onde o tremular das pacíficas fogueiras se está transformando em labaredas da revolta. O primeiro grande poeta moçambicano, Rui de Noronha, traduz então, na sua poesia, este sentimento nascente. "África, surge et ambula” é o primeiro grito alternativo; "Quenguêlêzê", a evocação tradicional da apresentação do recém-nascido à lua cheia, será premonitório do novo moçambicano que nasce.

Analisando a análoga conjuntura angolana, Rita Chaves escreve: “O apreço pelo passado corresponde à vontade de resistir e à convicção de que daquela ordem poderiam vir princípios para orientar a transformação já iniciada” (CHAVES, 1999, p.60).

Os escritores começam a viagem de reaproximação consigo próprios e com as referências que, reconciliando-os com os seus irmãos, lhes revelam uma identidade mais abrangente: a moçambicanidade, no caso do meu país.

As páginas e as revistas literárias são o campo de batalha onde se ensaiam soluções, se definem alianças, se trocam experiências, se buscam caminhos.

Em circunstâncias bem distintas como são as de Moçambique e Angola, devem-se a publicações literárias, o Itinerário e a Mensagem, respectivamente, os movimentos que se consideram marcantes na tomada de consciência nacional das duas literaturas.

Esses espaços podem, hoje, ser vistos como precursores das futuras zonas libertadas da luta armada de libertação. Ali se procura "manter o imaginário fora do processo de domínio do colonialismo" na feliz formulação de Alfredo Margarido. Ali se lê e se discute em liberdade, analisando o "inimigo" e preparando as ações que vão minar a sua estratégia de assimilação e despersonalização cultural. Ali se descobre a tensão no presente, entre o ontem e o amanhã, e a urgência em encontrar a linha de continuidade que liga a história pré-colonial e a resistência anti-colonialista. Só com esta o escritor resgatará a personalidade que lhe permitirá - como africano digno, homem livre e ator participante - entrar no futuro. Escrever é, assim, um 
momento decisivo de reflexão sobre as responsabilidades do escritor e sobre a relação entre a literatura e essa utopia vibrante e ainda imprecisa que é a nacionalidade.

Uma vez colocado perante o problema, nunca mais o escritor dele se vai livrar.

As grandes opções fazem-se então.

Alguns refugiam-se definitivamente na margem urbana. Delimitando os seus horizontes de inquietação e a sua pesquisa estética, dão costas a quanto sucede do outro lado; renunciam, por incapacidade ou por opção política e cultural, a compreender a realidade que os circunda e, sempre que a ela se referem, fazem-no de forma eurocêntrica, alienada, descritiva. Quando a sua sociedade perder espaço e debandar, eles debandarão com ela. Rodrigues Júnior é o melhor exemplo desta literatura colonial.

Outros, como Rui Knopfli, mantendo a sua base nos terrenos bem calcados da própria vivência europeizada, marcam a diferença que sentem pela relação física que estabelecem com a natureza e com os espaços moçambicanos. Mas esta relação permanece traumatizada porque a intimidade do diálogo com a terra se incompleta na ausência do diálogo com os homens e mulheres dessa terra. Buscam refúgio em referências que consideram universais, mesmo se circunscritas à cultura ocidental. Quando é proclamada a independência decidem ficar junto da terra mas, em breve, a incompreensão dos homens explicita a ruptura. A inabalável certeza na universalidade dos valores que a sua produção literária encerra não tem espaço para acomodar o "outro" e, quando deixam de dominar os princípios que norteiam as regras da convivência social, exatamente porque do "outro", o seu egocentrismo não lhes permite aceitar o próprio descentramento. Para eles, se a sua produção não é aclamada é porque, como escritores, são perseguidos. Não lhes resta senão a estrada do auto-exílio, onde vivem e escrevem recordando e exaltando tempos em que Moçambique não era independente. Não que louvem o colonialismo, mas recordam com nostalgia os tempos em que o seu anticolonialismo era parte de uma sociedade que entendiam.

Outros ainda, com opções mais ou menos radicais, buscam nas raízes novas abordagens, experimentam linguagens, procuram referências na tradição, na história ou na praxis anticolonial. É um esforço gigantesco e emocionante de identificação para poder retratar a terra e os homens de que se 
descobriram parte, para lhes restituírem, escrita, a História, para com eles interagirem como escritores e como cidadãos socialmente ativos.

Eles sabem que o fenômeno da luta armada de libertação nacional está destruindo velhas grilhetas e inibições. O processo é conduzido por uma nova elite político-militar que não é formada pelos intelectuais que vivem nas cidades. Mais uma vez, estes se apercebem de que é preciso a humildade de aprender o novo Moçambique que se forja nas matas e se constrói nas zonas libertadas.

A dialética da formação da identidade exige a clareza sobre os pontos de partida. E se são diversos os caminhos percorridos pelos nossos escritores, é mais ou menos pacífico para todos eles que a literatura moçambicana caminha, com maior ou menor ênfase, sobre dois carris: a língua portuguesa, como meio de expressão escrita e processo de inculturação - não como referente intertextual marcante - e a tradição oral (e agora a tradição inventada do processo revolucionário) como permanente busca de uma intertextualidade nacional.

Estes dois vetores interagirão com várias opções referenciais: as influências, imagens, símbolos do patrimônio socio-cultural e literário dos movimentos negros; o vigor e a analogia de situações e personagens das literaturas sulamericanas, de experiência anticolonial, e, em particular, dos escritores brasileiros; a revelação da pujante literatura da África recém-independente, percorrendo caminhos paralelos aos que inquietam os escritores moçambicanos e, finalmente, o grande reencontro no palco da revolução anticolonial traduzido numa produção literária engagée, populista e militante.

A esmagadora maioria dos escritores moçambicanos acaba por se situar nos meandros desta estrutura matricial associando, com tonalidades diversas, várias das influências referidas. José Craveirinha, Noêmia de Sousa, Rui Nogar, Kalungano seguem estradas diversas das percorridas, mais tarde, por Eduardo White, Armando Artur ou Luís Carlos Patraquim, mas não é difícil encontrar as afinidades referenciais nas obras desses poetas. Na mesma matriz se identificam as prosas de João Dias, Luís Bernardo Honwana, Mia Couto, Suleimane Cassamo e Ungulani Baka Kossa.

A questão fundamental da diferença na literatura de Moçambique situa-se no binômio influência ocidental - tradição oral. Os africanos, pela herança colonial e pelo poder hegemônico euro-americano, não poderíamos permanecer alheios às ressonâncias dessas propostas culturais que nos chegam do norte. Contudo, o Ocidente continua a não querer entender a Áfri- 
ca. A percepção da diversidade das realidades africanas permanece objeto constante de generalizações e é, com muita freqüência, folclorizante. As correntes mais bem intencionadas empenham-se em aferir os elementos distintivos - as concepções do tempo e de organização do espaço, as formas de encarar a morte e se relacionar com o passado, a percepção totalizante da realidade - mas são incapazes de os ver na sua dinâmica, como processo de luta para ocuparmos o nosso lugar de sujeito na História do mundo de que somos parte. A tendência é celebrar essa diferença, petrificando a cultura africana nos elementos que a distinguem.

Exatamente por isso, simplifica-se a atitude: e o mesmo Ocidente que invadiu o continente, explorou os africanos, violentou a sua cultura e alienou as suas elites, reclama a todo o momento, em plena era da globalização, uma cultura africana imaculada, uma imagem virtual a que o continente não pode corresponder. Uma imagem que, se fosse possível, forçaria os africanos a alienar-se da epopéia anticolonialista onde se reencontrou, como cidadão do século XX. Ao gritar ao escândalo quando o africano não é, em sua opinião, suficientemente tradicional, o Ocidente denuncia como contaminado o que de melhor tem produzido a literatura africana contemporânea e, num cínico ato de contrição, propõe que voltemos atrás, às nossas culturas despoluídas, para retomar a nossa estrada a partir do momento histórico em que o colonialismo, desvalorizando a linguagem, o vestuário e a técnica do colonizado, esterilizou as culturas africanas.

Ignora-se, com assustadora freqüência, que a luta pela independência foi também motivada pelo desejo de romper com o imobilismo e a incomunicabilidade que o colonialismo fomentou entre as diversas realidades culturais de Moçambique.

Ao contrário, a natureza popular e igualitarista dos governos saídos dessas lutas sugeria que as duas margens de diferenciação da sociedade colonial seriam aproximadas. Mesmo tendo sido fugaz, esse momento representou, para o intelectual empenhado e para o criador artístico, uma oportunidade incomparável de síntese, de aprendizagem e de reflexão.

A imersão nas manifestações culturais localizadas permitiu compreender as suas profundas raízes na tradição e conhecer os valores mais genuínos de que são portadoras. Porém, o intelectual apercebeu-se também de como elas são, quase sempre, inalienáveis dessa totalidade que é a socieda- 
de camponesa. Daí, a dificuldade de trânsito para uma realidade sempre mais tecnológica, massificada, mercantilizada.

Com excepção, em casos muitos especiais, da escultura, todas as outras formas de expressão artística tradicional, ao serem cooptadas para a esfera da cultura pós-industrial, destinada ao consumo e audiências interculturais, perdem identidade. Imperativos de mercado, fundamentalmente, exigem a sua "tradução" nos códigos sempre mais globalizados da indústria da cultura de massa.

A literatura não foge completamente a esse dilema. Também ela é uma arte que, situada fora do universo da sociedade oral, traz em si elementos que, com maior ou menor intensidade, exprimem superioridade. $\mathrm{O}$ seu encontro com a tradição oral é complexo. A oratura não é só a palavra falada. $\mathrm{O}$ contador de estórias é tão mais artista quanto mais rica forem as expressões, os gestos, as interjeições, as entoações da voz e os silêncios. A eficácia e o brilhantismo do seu texto oral são acentuados pela luz da fogueira que o ilumina, pela copa acolhedora da árvore sob a qual decorre a narrativa, pela ritualidade solene do próprio ato de evocação do passado e de transmissão dos seus ensinamentos.

A recuperação da oratura, importante para a busca de referências literárias na tradição, deve encontrar formas de se relacionar com aquela questão. A mera transcrição, mais do que insuficiente, atenta contra uma forma artística que tem existência autônoma.

Manuel Rui, escritor angolano, assim o pensa: "E mesmo que registe o texto oral para estruturas diferentes - as da escrita - a partir do momento em que o escreva e procure difundi-lo por esse registo, quase assumo a morte do que foi oral..." (RUI,1981,p.29). "No entanto, eu letrado - anuncia Manuel Rui -, introduzo no meu texto contextos do nómada" (idem, p.30).

A tradição oral não se transforma em escrita; no melhor dos casos ela vai contaminá-la, introduzir matizes, sem nunca, contudo, a dominar.

O caminho possível não é, pois, o da fusão das duas margens mas o da identidade plural: "Eu e o nómada, cada um de nós, singular, não pode ser ele próprio sem nos pluralizarmos", conclui Manuel Rui (1981, p. 34).

Só na realização da Utopia - fundada na justiça, na liberdade, no progresso e na convergência dos destinos entre o Povo e o intelectual, entre a prática e a teoria - se resolveria a questão da dualidade. 
As duas margens simbólicas sobreviveram, portanto, à convulsão libertária, mesmo se reaproximadas e reconhecendo-se, visitando-se e trocando experiências. A identidade do escritor desce do projeto da Utopia para o patamar do possível e essa identidade viável vai sendo descoberta através de um doloroso processo esquizóide. O intelectual e o artista permanecem confrontados com os chamamentos e os estímulos dos dois mundos e com a imagem que os dois mundos têm de si.

Eu disse, acima, que o escritor, uma vez confrontado com o problema da identidade, nunca mais dele se vai livrar. É esse o seu destino e é essa a riqueza da literatura de que é sujeito e complemento.

Quando, amadurecido por uma experiência de pesquisa e de combates, ele julga estar-se encontrando como produtor literário, quando se sente reconciliado com a própria identidade, quando o seu país começa a ter meios para publicar a sua obra, vê-se confrontado com o mesmo problema que chocou os fundadores da nossa televisão em 1981. Escrever para quem, numa sociedade ainda predominantemente oral? Para a minoria urbana? Para o público de língua portuguesa extra-fronteiras? Como ensina o Prof. Antonio Candido, a literatura existe efetivamente quando se completa o ciclo autorobra-leitor. Esta é uma questão em aberto que espreita perigosamente sobre o ombro dos nossos escritores que mais uma vez se encontram dilacerados entre os dois mundos que marcam a sua vida.

\section{BIBLIOGRAFIA}

CHAVES, Rita. A formação do romance angolano. São Paulo: Edusp/FBLP, Coleção Via Atlântica, 1999.

FANON, Frantz. Os condenados da terra. Lisboa: Editora Ulisseia, s/ data. RUI, Manuel. “Comunicação”. In: Teses angolanas. Lisboa: Edições 70, UEA, 1981, v.1. 